\title{
Ranking of E-Health Barriers Faced by Saudi Arabian Citizens, Healthcare Professionals and IT Specialists in Saudi Arabia
}

\author{
Saleh Almuayqil1,2, Anthony S. Atkins' ${ }^{2}$, Bernadette Sharp² \\ ${ }^{1}$ College of Computer Sciences and Information, Aljouf University, Sakaka, The Kingdom of Saudi Arabia \\ ${ }^{2}$ School of Computing, Staffordshire University, Stafford, UK \\ Email: saleh.naif@ju.edu.sa
}

Received 15 June 2016; accepted 24 July 2016; published 27 July 2016

Copyright (C) 2016 by authors and Scientific Research Publishing Inc.

This work is licensed under the Creative Commons Attribution International License (CC BY). http://creativecommons.org/licenses/by/4.0/

C) (i) Open Access

\begin{abstract}
Many boundaries are hindering successful utilisation of e-health in the Kingdom of Saudi Arabia (KSA). We have previously proposed an integrated framework of knowledge management and knowledge discovery to overcome barriers of e-health in KSA. Our proposed framework facilitates diabetes self-management for diabetic citizens in the Kingdom. In this paper, we will investigate and rank the barriers of e-health in KSA from the prospective of three stakeholders. We designed a questionnaire which constituted of items related to eight different e-health barriers and its associated sub-barriers. Citizens participated in 51 items related to six barriers. Healthcare professionals answered 83 items related to eight barriers. IT specialists participated in 74 items related to six barriers. Within each group of respondents, we compared the mean scores for each factor and sub-factor. The highest possible score for the mean was 5.00 and the lowest was 0.00 where the higher the mean score was the more the barrier constituted an obstacle for e-health in KSA. Citizens ranked the connectivity of information system as the top barrier with the mean of 4.0 whereas the least barrier was the cultural barriers with the mean score of 3.1. Healthcare professionals ranked the connectivity of information systems as the top barriers with the mean score of 3.5 whereas the least barrier was the technical expertise and computer skills with the mean score of 2.2. The top ranked barrier from the perspective of IT specialists was the medication safety with the mean score of 3.5 and the least ranked barrier was security and privacy with the mean score of 2.2. The results showed consistency with the literature review. Our proposed framework will contribute to the successful implementation of e-health initiatives and assist citizens in KSA to selfmanage diabetes.
\end{abstract}

\section{Keywords}

E-Health Barriers, Knowledge Discovery, Knowledge Management, The Kingdom of Saudi Arabia 


\section{Introduction}

Healthcare organisations in the Kingdom of Saudi Arabia (KSA) are investing substantial effort and expenditure to adopt e-health successfully. However, such implementation has been impacted by many barriers. The literature review has identified several e-health barriers in KSA which could impede such integration. We have previously proposed an integrated framework of knowledge management and knowledge discovery to help to overcome e-health barriers [1]. As KSA is in the top countries in the prevalence of diabetes mellitus, our proposed framework also aims to assist Saudi Arabian citizens to self-manage their disease and obtain better education about diabetes. To address this critical factor, a survey of e-health barriers has been carried out to understand the nature of these issues and current attitudes of Saudi societies, and consequently help to propose solutions to overcome these obstacles. The barriers of e-health in KSA belong to four main components, as highlighted in Figure 1. The aim of this paper is to rank the barriers of e-health in KSA from the perspectives of Saudi Arabian citizens, healthcare professionals, and IT specialists. For this purpose, we conducted a questionnaire to investigate the e-health barriers documented in the literature. The questionnaire study, the results and discussion are presented in this paper.

\section{Experimental Study}

\subsection{Methodology}

The first task is to investigate the barriers associated with e-healthcare and electronic health records (EHR) in KSA among the potential users of our proposed framework. We have designed a questionnaire to survey and rank the issues and attitudes of three stakeholders from the four components: business, human, technology, and financial factors. Perceived participants are citizens who may use healthcare services, healthcare professionals who work in the healthcare sector, and specialists of IT who support healthcare organisations. The areas of study are summarised in Table 1 and consists of the following factors:

Participants were asked to complete two sections. The first section consists of five questions to gather demographical information. The second section includes two types of multiple choice questions where each participant is asked to read statements related to e-healthcare barriers and chose the most accurate option. The first type of multiple choice questions have the options yes, no and I don't know. Whereas the other type of options have the options of strongly agree, moderately agree, neutral, moderately disagree, strongly disagree and I don't know. The option of "I don't know” is provided to avoid forcing respondents to answer [2]. Options for all questions were coded. However, some items were presented in positive statements and others in negative. Consequently, reverse recoding technique is used with some scales to ensure coding consistency [3].

\subsection{Ethical Consideration}

We gained ethical approval prior to generating our questionnaire. The participations included adult citizens,

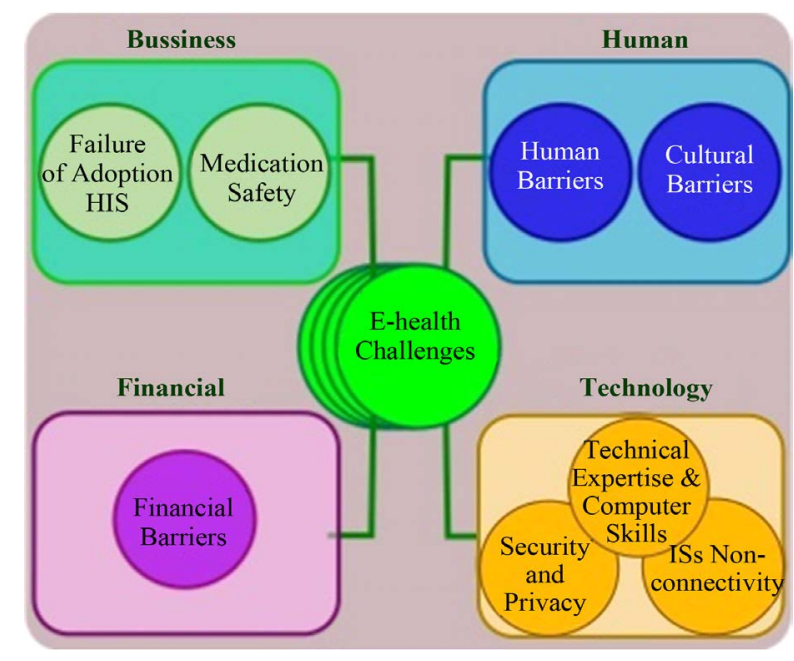

Figure 1. Component of e-health barriers in KSA. 
Table 1. Areas of study-barriers to e-health.

\begin{tabular}{|c|c|c|c|c|}
\hline Areas of study & Sub-factors & Citizens & $\begin{array}{l}\text { Healthcare } \\
\text { professionals }\end{array}$ & IT specialists \\
\hline Non-connectivity of ISs & Lack of national healthcare system & $\sqrt{ }$ & $\sqrt{ }$ & $\sqrt{ }$ \\
\hline $\begin{array}{l}\text { Technical expertise and } \\
\text { computer skills }\end{array}$ & $\begin{array}{l}\text { Interface design, guidelines, experience in computer } \\
\text { applications, access and maintenance }\end{array}$ & $\sqrt{ }$ & $\sqrt{ }$ & $\sqrt{ }$ \\
\hline Failure of adoption of HISs & $\begin{array}{l}\text { Planning, technical support and running over } \\
\text { time/cost }\end{array}$ & & $\sqrt{ }$ & $\sqrt{ }$ \\
\hline Human barriers & $\begin{array}{l}\text { Negative believes, lack of trust and resistance to } \\
\text { change }\end{array}$ & $\sqrt{ }$ & $\sqrt{ }$ & \\
\hline Cultural barriers & Human interaction & $\sqrt{ }$ & $\sqrt{ }$ & \\
\hline Meciation safety & Limited use of technology and communication gap & & $\sqrt{ }$ & $\sqrt{ }$ \\
\hline Financial barriers & Financial barrier & $\sqrt{ }$ & $\sqrt{ }$ & $\sqrt{ }$ \\
\hline Security and privacy & Easy to access patients' medical records & $\sqrt{ }$ & $\sqrt{ }$ & $\sqrt{ }$ \\
\hline
\end{tabular}

healthcare professional and IT specialists in KSA; the respondents' identities were anonymous and participants were allowed to withdraw at any stage. Our study did not seek any participation from children, people with communication or learning difficulties, patients, people in custody, people who can be considered vulnerable or people engaged in illegal activities.

\subsection{Pilot Study}

A pilot study was conducted in order to ensure the formalisation of the questions and identify any ambiguous and unclear questions or issues. Some modifications were carried out related to the phrasing of some of the questions, others to grammar and spelling mistakes.

\subsection{Data Analyses}

For the purpose of ranking e-health barriers from different perspectives, we compared the mean scores for each factor and sub-factor within each group of respondents. The highest possible score for the mean was 5.00 and the lowest was 0.00 where the higher the mean score is the more the barrier constitutes an obstacle. Based on the paper by Haener and Adamowicz [4], the responses of "I don't know" and "I'm not sure" were eliminated from the analysis. Simple proportional transformation was used to enable comparison between the two types of scales we used in this study [5] [6].

\section{Results of the Questionnaire}

\subsection{Respondents' Profile}

The number of participants who completed the questionnaire is 201 (69.7\%). Respondents' profile informations are summarised in Table 2.

\subsection{Business Component}

\subsubsection{Failure of Adoption of Health Information Services (HIS)}

Healthcare professionals indicated issues in technical support sub-factor. Most healthcare professionals complained about the lack of availability of technical support $(n=9,52.9 \%)$ slow responses of EHRs $(n=11,64.7 \%)$ and its inability to view their patients' progress $(n=11,64.7 \%)$.

The majority of IT specialists indicated barriers related to planning sub-factor as most IT specialists complained that EHRs was adopted without partnership with patients $(\mathrm{n}=14,34.1 \%)$. In addition, they indicated that the time needed for adoption EHRs was not clearly identified $(n=11,26.8 \%)$. The sub-factors related to technical support and running over time/cost were positively indicated as a critical issue in considering the adoption of e-healthcare.

Healthcare professionals reported higher mean regarding the failure of adoption HIS (mean $=2.8$ ) than IT 
Table 2. Profile of respondents to the questionnaire.

\begin{tabular}{|c|c|c|c|}
\hline Items & $\mathbf{N}$ & $\%$ & Total \\
\hline \multicolumn{4}{|c|}{ Please specify your gender } \\
\hline Male & 156 & 78 & \multirow{2}{*}{201} \\
\hline Female & 45 & 22 & \\
\hline \multicolumn{4}{|c|}{ Please specify your age } \\
\hline $18-30$ & 64 & 32 & \multirow{5}{*}{201} \\
\hline $31-40$ & 98 & 49 & \\
\hline $41-50$ & 31 & 15 & \\
\hline $51-60$ & 7 & 3 & \\
\hline Over 60 & 1 & 0 & \\
\hline \multicolumn{4}{|c|}{ Please specify your educational level } \\
\hline High school & 10 & 5 & \multirow{4}{*}{201} \\
\hline Bachelor & 110 & 55 & \\
\hline Master & 65 & 32 & \\
\hline Doctoral & 16 & 8 & \\
\hline \multicolumn{4}{|c|}{ Please specify your computer skills } \\
\hline Low & 15 & 7 & \multirow{3}{*}{201} \\
\hline Medium & 127 & 63 & \\
\hline High & 59 & 29 & \\
\hline \multicolumn{4}{|c|}{ Please specify your role in the healthcare sector } \\
\hline Citizen & 117 & 58 & \multirow{3}{*}{201} \\
\hline Medic/healthcare & 43 & 21 & \\
\hline IT specialists & 41 & 20 & \\
\hline
\end{tabular}

specialists (mean $=2.7)$. Other issues identified by the healthcare professionals were lack of technical support (mean $=3.4$ ) and planning (mean $=2.7$ ). IT specialists mean scores for the sub-factors were running over time/ cost (mean $=2.8)$, lack of technical support $($ mean $=2.7)$ and lack of planning (mean $=2.2)$.

\subsubsection{Medication Safety}

Stakeholders, the healthcare professionals and IT specialists have not identified any issues in relation to medication safety. The mean for the IT specialists is slightly higher (mean $=3.7$ ) than the healthcare professionals (mean $=2.5$ ). Regarding the limited use of technology sub-factor IT specialists scoring is higher (mean $=4.2$ ) than the sub-factor related to communication gap (mean $=3.4$ ). Healthcare professionals reported lower mean scores for limited use of technology (mean $=2.7$ ) and communication gap (mean $=2.5)$.

\subsection{Human Component}

\subsubsection{Human Barriers}

Regarding the human barriers, citizens have indicated critical issues throughout this component. In the negative believes sub-factor, almost half of the citizens believe that EHRs can create technical problems $(n=56,47.9 \%)$, legal problems $(n=58,49.6 \%)$ and administrative problems $(n=50,42.7 \%)$. Furthermore, the majority of citizens believe that EHRs are beneficial for healthcare professional but not for citizens ( $n=54,45.8 \%$ ). The same number believe that implementation of EHRs can decrease productivity of healthcare professionals $(n=45$, 46.2\%). The results from the lack of trust sub-factor were similar; the majority of citizens think their EHRs can be out of date ( $n=66,56.4 \%$ ), using EHRs can be complicated ( $n=55,47.0 \%)$, EHRs can give incorrect infor- 
mation regarding medication $(n=59,50.4 \%)$, medication dates $(n=55,47.0 \%)$ and laboratory test results $(n=53$, 45.3\%). They also think that EHRs can allow unauthorised people to access their information ( $\mathrm{n}=66,56.4 \%$ ). In relation to the resistance to change, most citizens believe that changing to e-health requires long time to be accomplished $(\mathrm{n}=70,59.8 \%)$ and such a change needs to train patients in how to use e-health solutions ( $\mathrm{n}=89$, 76.1\%). Citizens also believe that implementation of health information systems will reduce job opportunities $(\mathrm{n}=$ 64, 54.7\%) and using EHRs will affect their relationship with their doctors $(n=55,47.0 \%)$.

Healthcare professionals indicated issues with respect to the lack of trust sub-factor as most of them believe that their patient's records can be out of date $(n=21,48.8 \%)$. Furthermore, the results from the resistance to change sub-factor indicated that healthcare professionals believe that changing to e-health requires long time to be accomplished $(n=26,60.5 \%)$. They also believe such a change will reduce job opportunities $(n=16,37.2 \%)$ and need special training in how to use e-health solutions ( $n=36,83.7 \%)$. Citizens scored the highest mean score in relation to this factor (mean $=3.9$ ). Resistance to change reported the mean score $($ mean $=4.0)$ higher than other sub-factors; lack of trust (mean = 3.7) and negative believes (mean = 3.6). Healthcare professionals, on the other hand, had lower mean scores for human barriers than citizens (mean $=2.6$ ) with the sub-factors ranking resistance to change (mean $=2.8)$, lack of trust (mean $=2.7)$ and negative beliefs $($ mean $=2.4)$.

\subsubsection{Cultural Barriers}

Most of the citizens indicated their preference of human interaction in relation to receipt healthcare service. Citizens prefer to meet with their doctors to get information about their medications ( $\mathrm{n}=76,65.0 \%)$. In addition, high number of citizens prefer paper based records medical records $(n=43,36.8 \%)$ and see EHRs less detailed than the traditional ones $(n=54,46.2 \%)$.

Similarly, most healthcare professionals prefer meeting with their patients to provide them with the medical information they need $(n=30,69.8 \%)$. No other cultural barriers were identified by the healthcare professionals' perspectives. Both citizens and healthcare professionals shared the same mean score for the preference of human interaction sub-factor (mean $=3.1$ ).

\subsection{Technology Component}

\subsubsection{Connectivity of Information Systems}

More than half of the citizens do not use EHRs $(n=60,51.3 \%)$. The majority of citizens are not sure if they have the ability to use and access their EHRs in more than one hospital in KSA ( $n=29,50.9 \%)$. The healthcare professionals share similar concerns as most of them do not use EHRs ( $\mathrm{n}=22,51.2 \%)$. Healthcare professionals who use EHRs stressed their use of such records in more than one hospital ( $n=11,64.7 \%)$. However, they indicated their inability to view patients’ EHRs, update laboratory test results for patients who are visiting from other hospitals and disseminate patients' records electronically to other hospitals in the country.

More than half of IT specialists insisted that EHRs are used in more than one hospital in KSA ( $n=23,56.1 \%$ ). Twenty-three IT specialists expressed serious concerns regarding their inability to share patients' information electronically, to access patients' records in other hospitals electronically, to electronically update exchanged patients' EHRs, and lack of both, integration among EHRs of using structure standards. However, they perceived some benefits of EHRs such as the utilisation of vocabulary standards, the ability of other EHRs systems to understand and process exchanged information and the support of EHRs of national healthcare strategies.

However, IT specialists also indicated that the IT infrastructure in the healthcare sector in the Kingdom is not ready to have national EHRs system $(n=20,49.0 \%)$. The majority of those complained of out of date computer networks ( $n=8,40.0 \%)$, insufficient storage capacity $(n=10,50.0 \%)$, old servers $(n=8,40.0 \%)$, old routers $(\mathrm{n}=7,35.0 \%)$ and lack of development of national healthcare system $(\mathrm{n}=17,85.0 \%)$.

The mean score for this factor varies among citizens, healthcare professionals and IT specialists. Citizens scores the highest mean in this aspect (mean $=4.0)$ whereas the IT specialists had the lowest score $($ mean $=3.1)$. The score for the healthcare professionals were in the middle (mean $=3.5$ ).

\subsubsection{Technical Expertise and Computer Skills}

Citizens indicated difficulties in using EHRs ( $n=44,77.2 \%)$, related to difficult terminologies $(n=46,80.7 \%)$, inaccurate information $(n=40,70.2 \%)$ and inability to modify personal information ( $\mathrm{n}=45,78.9 \%)$. Most of the respondents from the citizens complained about the absence of guidelines $(\mathrm{n}=44,77.2 \%)$ and training $(\mathrm{n}=$ 
53, 93.0\%) for using their EHRs. Inadequacy of internet speed was also indicated $(n=61,52.1)$ as well as deficiency in maintenance of computers $(n=62,53.0 \%)$ and internet connections $(n=74,63.2 \%)$. Factors related to the experience in using computer applications resulted in positive indications as the majority of citizens use computers to browse the internet, check their emails, accomplish tasks at work and download applications skillfully. Similarly, most citizens have access to a computer to check their emails and browse the internet.

Similar to citizens, healthcare professionals stressed the difficulty of EHRs ( $\mathrm{n}=7,41.2 \%)$ and inaccuracy of its information ( $n=9,52.9 \%$ ), not surprisingly most healthcare professionals disagreed that EHRs use difficult terminologies $(\mathrm{n}=10,58.8 \%)$. Most of the healthcare professionals' respondents have been trained in how to use EHRs ( $\mathrm{n}=12,70.6 \%)$ and the majority of them were provided with guidelines in how to use them $(\mathrm{n}=7$, 46.7\%). A large number of healthcare professionals complained about deficiency in maintaining internet connection $(n=20,46.5 \%)$. No major issues were raised in relation to computers speed, internet connection speed and computers maintenance. Similarly, no issues were expressed related to their computing experience and insufficient access of computers.

Similar to the previous factor, the mean scores for this barrier placed the citizens first (mean $=3.2$ ). The no guidelines sub-factor constituted the overall mean of this factor (mean $=4.7$ ) and then the poor interface design sub-factor (mean $=4.5)$. Other sub-factors were poor maintenance (mean $=3.34$ ), insufficient access (mean $=$ 2.7) and lack of experience in computer applications (mean $=2.1$ ).

IT specialists scored the second highest mean (mean $=2.6$ ) with the lack of experience in computer application as the highest sub-factor (mean $=3.9$ ). The remaining sub-factors were poor maintenance (mean $=2.4$ ), insufficient access and no guidelines (mean $=2.4$ ) and the least constituter of this barrier were poor interface design (mean $=2.2$ ). Healthcare professionals had the lowest mean score in the technical expertise and computer skills factor (mean $=2.2$ ). Poor interface design constituted the majority of this factor (mean $=2.9$ ). Other sub-factors were poor maintenance (mean $=2.8$ ), no guidelines $($ mean $=2.7$ ), insufficient access $($ mean $=1.9$ ) and the least constituter were the lack of experience in computer applications (mean $=1.5$ ).

\subsubsection{Security and Privacy}

Citizens and IT specialists did not report any issue in relation to security and privacy factors. However, the majority of healthcare professionals reported security and privacy issues in relation to the ease of accessing records of the patients. Most healthcare professionals identified the issue of accessing their patients' EHRs without their permission $(n=9,52.9 \%)$. More than one-third complained that their patients' EHRs were disseminated and updated without their permission ( $\mathrm{n}=7,41.2 \%)$. Almost half of the healthcare professionals indicated that they are not able to control the access of others to their patients' EHRs $(n=8,47.1 \%)$ and the same number of respondents had access to other patients' EHRs they are not authorised to. More than half of healthcare professionals are not able to determine who should see their patients' EHRs $(n=9,52.9 \%)$. The majority of healthcare professionals also complained that they are not informed of people who had access to their patients' EHRs ( $\mathrm{n}=$ 11, 64.7\%). High number of healthcare professionals also expressed that they had the ability to control other patients' health records $(n=6,37.5 \%)$.

Mean score from the citizens were the highest among the other two groups of respondents (mean $=3.5$ ). Healthcare professionals reported the second highest mean in this factor (mean $=3.2$ ) whereas the lowest mean score resulted from the IT specialists (mean $=2.2$ ).

\subsection{Financial Component}

IT specialists are the only group of respondents who confirmed the existence of financial barrier. More than half of the IT specialists think that adoption of e-health needs high expenditure $(\mathrm{n}=25,61.0 \%)$. In addition, most respondents expressed funding difficulties for the adoption of EHRs $(n=18,43.9 \%)$.

Citizens reported their concerns with this issue more than the other two groups of respondents (mean = 3.7). The mean score from IT specialists were lower than citizens' (mean = 3.5). Healthcare professionals highlighted this issue least frequent among other participants as the mean score they reported were the lowest (mean = 2.7).

\section{Discussion}

\subsection{Citizens}

The findings from the citizen's respondents confirmed the existences of the six barriers which were identified in 
the literature. Our findings from the factor related to the connectivity of information systems showed that this barrier is the first reason that hinders successful implementation of e-health in KSA. The second most important barrier for e-health from citizens' data is the human barriers factor. Sub-factors such as negative beliefs, lack of trust, and resistance to change were identified in the literature as main causes of failure for adoption HIS [7]. Citizens ranked financial barriers in third place and [8] has studied financial cost of utilisation of EHRs and suggested a feasibility study prior to such utilisation. The fourth barrier, related to security and privacy, is an important concern for the citizens though most citizens responded neutrally. Technical expertise and computer skill were also identified as a critical barrier of e-health in the Kingdom. The findings from the citizens indicated consistency with the literature in terms of lack of providence of guidelines for handling EHRs, low internet speed, deficient maintenance of computers and internet connections [8]. Cultural barriers are the lowest impact factor which can hinder e-health in the Kingdom. Citizens' results were similar to Aldraehim and Edwards findings [9] where the need for human interaction is preferable by Saudi Arabian people. Figure 2 summarizes the ranking of the e-health barriers from the citizens' point of view.

\subsection{Healthcare Professionals}

Even though the ranking of e-health barriers from the healthcare professionals' perspective starts with the connectivity of information systems, their data indicates inconsistency with the literature as most of them use EHRs in more than one hospital [10]. Based on our findings, this is due to the fact that most of them do not use EHRs for their patients. In addition, many healthcare professionals expressed their inability to perform viewing, updating and disseminating EHRs and laboratory test results of patients who are visiting from other hospitals.

Cultural barriers were ranked secondly by the majority of healthcare professionals. Human interaction is most preferred by Saudi Arabian people [9]. The findings in our study are consistent with the literature as many healthcare professionals prefer meeting with their patients face to face in order to provide tailored medical information to their patients.

The third ranked e-health barrier from the healthcare professionals' point of view is security and privacy. Our findings are consistent with Khalifa [8] who documented the dissemination of patients' medical records without a permission from the patient or his/her doctor. In addition, factors related to the ability of accessing their patients' records from unauthorised people, the inability to be informed of such access was their second greatest concern.

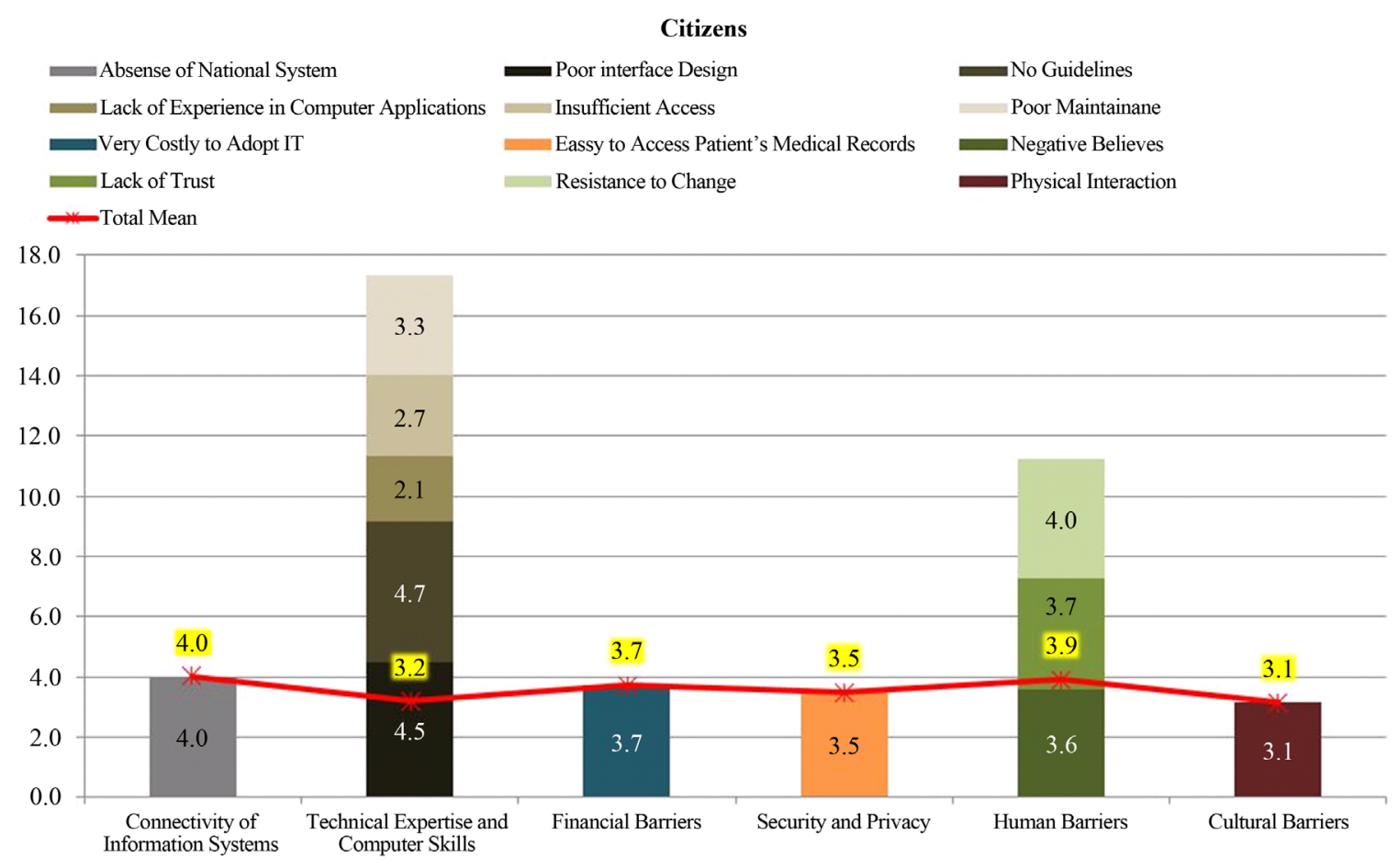

Figure 2. Ranking of e-health barriers in KSA from the citizens’ perspective. 
Healthcare professionals ranked failure of adoption of HIS as the fourth e-health barrier in KSA as they complained their inability to view their patients' progress. They also indicated slow responses of EHRs and lack of availability of technical support, which is similar to the poor technical support reported by [8] [9].

Although our findings did not identify critical financial issues from healthcare professionals, the ranking of this factor is held in the fifth place. Our findings show that lack of trust on EHRs and resistance to change to e-health from traditional health approaches are dominant concerns. These issues are also raised by [7], who considered them as the biggest indication of failing to adopt HISs.

Medication safety and technical expertise and computer skills are the least ranked e-health barriers by healthcare professionals. Our findings do not show issues related to the medication safety factor. However, the technical expertise and computer skills factor was complained by healthcare professionals especially regarding the deficient internet maintenance, difficulty of using EHRs and inaccuracy of its information. These issues were documented by [8] along with other factors related to technical expertise and computer skills (see Figure 3).

\subsection{IT Specialists}

The ranking from IT specialists in KSA differed from Saudi Arabian citizens' and healthcare professionals' ranking. As citizens and healthcare professionals corresponded in their first ranked barrier, connectivity of information systems, IT specialists started their ranking differently by ranking the medication safety as the top e-health barrier in the Kingdom. Moreover, the third stakeholder group ended their ranking with different boundary, security and privacy, as the least barrier that impedes e-health solutions in KSA.

The findings from IT specialists indicated that medication safety has the highest ranked mean score among other barriers. The second ranked barrier relates to the financial barriers. As [11] described, IT specialists stressed the importance of e-health expenditure investment involved in providing e-health services.

IT specialists ranked connectivity of information systems as the third barrier that hinders the e-health adoption in KSA. As Altuwaijri [10] has explained in his paper, our findings confirmed the issues raised in relation to the inability to access, update, share and integrate EHRs of patients.

Although only few IT specialists complained about their technical expertise and computer skills, this factor is ranked as the fourth barrier in their scale. Furthermore, most of IT specialists support the adoption of HIS factor if the partnership issue with patients is addressed. This finding is also identified in the literature as one important

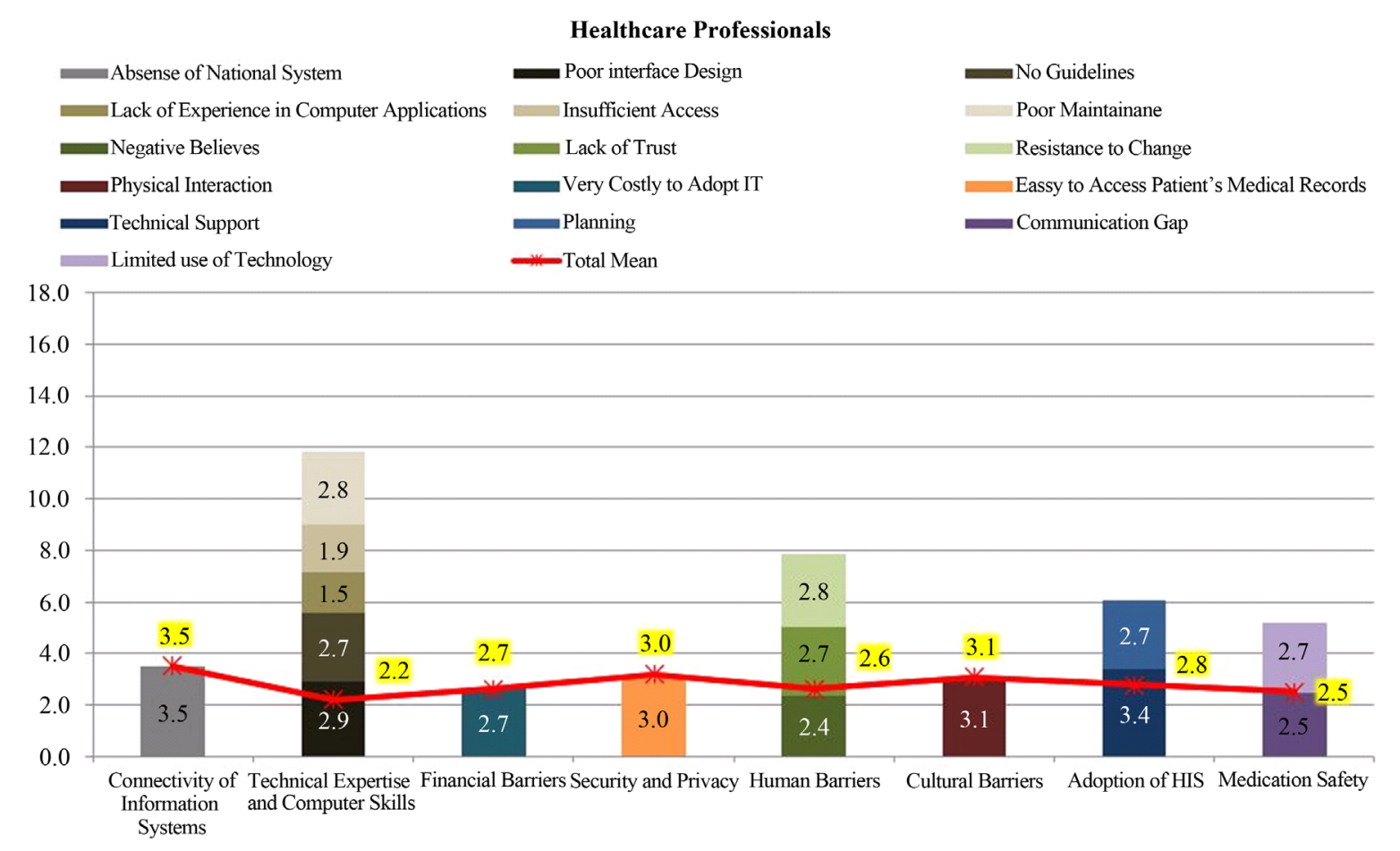

Figure 3. Ranking of e-health barriers in KSA from the healthcare professionals’ perspective. 


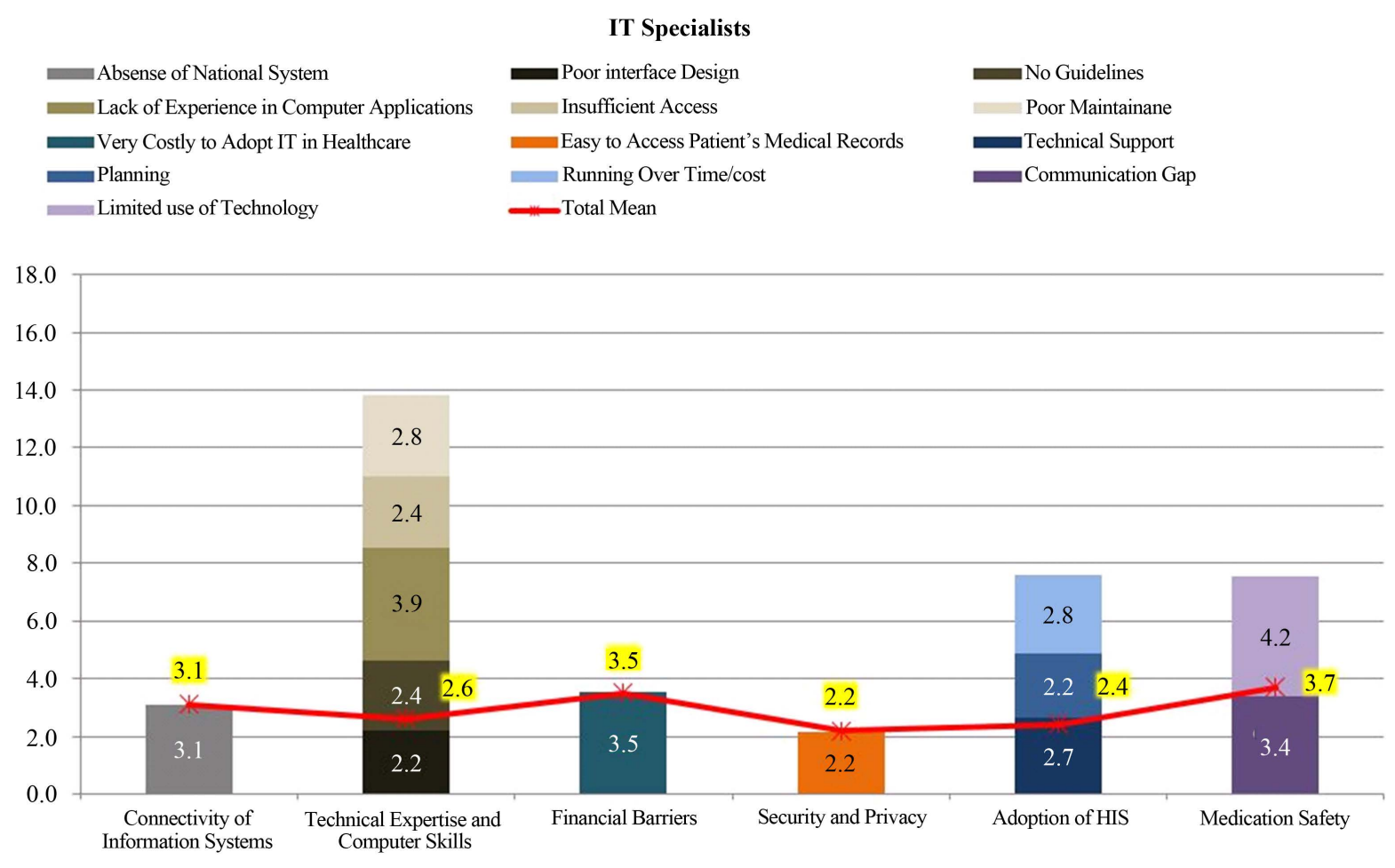

Figure 4. Ranking of e-health barriers in KSA from the IT specialist’ perspective.

reason for failing to adopt HISs [8] [9].

Security and privacy is ranked as the sixth reason that impedes the adoption of e-health in KSA. The literature has identified many factors that can affect privacy of patients' information such as ease of access to such information without permission [8]. On the contrary, respondents from the IT specialists group stressed the use of various security and privacy mechanisms to ensure confidentiality of patients' information. IT specialists' ranking of e-health barriers is shown in Figure 4.

\section{Conclusion}

Ranking e-health barriers in KSA from the perspectives of Saudi Arabian citizens, healthcare professionals and IT specialists will enable the provision of solutions for each stakeholder. Eight factors which were identified from the literature were perceived to be hindering e-health utilisation in KSA. In this research, we investigated the eight barriers and ranked them from the point of view of each group of respondents. The analysis of the questionnaire shows that citizens and healthcare professionals perceive the lack of connectivity of HISs in KSA to be the main reason for the failure of e-health, whereas IT specialists believe that the lack of medication safety is the biggest obstacle factor leading to such a failure. The results will assist us in developing a knowledge management system to assist healthcare and IT professionals to provide the best support to diabetic citizens in KSA. Additionally, the finding of this study can contribute on successful utilization of other e-health initiatives in the Kingdom such as electronic health records, telemedicine and the implementation of cloud computing in healthcare.

\section{References}

[1] Almuayqil, S., Atkins, A.S. and Sharp, B. (2015) Integrated Framework of Knowledge Management and Knowledge Discovery to Support E-Health for Saudi Diabetic Patients. International Journal on Advances in Life Sciences, 7, 111121.

[2] Wang, H. (1997) Treatment of “Don’t-Know” Responses in Contingent Valuation Surveys: A Random Valuation Model. Journal of Environmental Economics and Management, 32, 221. http://dx.doi.org/10.1006/jeem.1996.0965

[3] Sims, R.L. (2000) Bivariate Data Analysis; a Practical Guide. 2nd Edition, Nova Science Publishers, Portland. 
[4] Haener, M.K., Adamowicz, W.L., et al. (1998) Analysis of “Don’t Know” Responses to Referendum Contingent Valuation Questions. Agricultural and Resource Economics Review, 27, 218-230.

[5] Colman, A., Morris, C. and Preston, C. (1997) Comparing Rating Scales of Different Lengths: Equivalence of Scores from 5-Point and 7-Point Scales. Psychological Reports, 80, 355-362. http://dx.doi.org/10.2466/pr0.1997.80.2.355

[6] Sambandam, R. (2006) Scale Conversions.

[7] Altuwaijri, M. (2011) Implementation of Computerized Physician Order Entry in National Guard Hospitals: Assessment of Critical Success Factors. Journal of Family and Community Medicine, 18, 143-151. http://dx.doi.org/10.4103/2230-8229.90014

[8] Khalifa, M. (2013) Barriers to Health Information Systems and Electronic Medical Records Implementation. A Field Study of Saudi Arabian Hospitals. Procedia Computer Science, 21, 335-342. http://dx.doi.org/10.1016/j.procs.2013.09.044

[9] Aldraehim, M. and Edwards, S. (2013) Cultural Impact on E-Service Use in Saudi Arabia: The Need for Interaction with Other Humans. International Journal of Advanced Computer Science, 3, 10.

[10] Altuwaijri, M. (2008) Electronic-Health in Saudi Arabia. Just around the Corner? Saudi Medical Journal, 29, $171-178$.

[11] Amatayakul, M. (2010) Keys to Successful EHR Implementation. Healthcare Financial Management: Journal of the Healthcare Financial Management Association, 64, 104-104.

\section{Submit or recommend next manuscript to SCIRP and we will provide best service for you:}

Accepting pre-submission inquiries through Email, Facebook, LinkedIn, Twitter, etc.

A wide selection of journals (inclusive of 9 subjects, more than 200 journals)

Providing 24-hour high-quality service

User-friendly online submission system

Fair and swift peer-review system

Efficient typesetting and proofreading procedure

Display of the result of downloads and visits, as well as the number of cited articles

Maximum dissemination of your research work

Submit your manuscript at: http://papersubmission.scirp.org/ 